\title{
Compression Therapy in the Management of Cellulitis: A Comparative Study
}

\author{
Kipsang Joseph ${ }^{1}$, Nangole Wanjala ${ }^{2}$, Khainga Stanley ${ }^{2}$ \\ ${ }^{1}$ Department of Surgery, Bungoma County Hospital, Bungoma, Kenya \\ ${ }^{2}$ Department of Surgery, University of Nairobi, Nairobi, Kenya
}

Email address:

nangole2212@gmail.com (N. Wanjala)

To cite this article:

Kipsang Joseph, Nangole Wanjala, Khainga Stanley. Compression Therapy in The Management of Cellulitis: A Comparative Study. Journal of Surgery. Vol. 6, No. 3, 2018, pp. 68-72. doi: 10.11648/j.js.20180603.13

Received: March 31, 2018; Accepted: April 17, 2018; Published: May 10, 2018

\begin{abstract}
Cellulitis is a common condition causing significant morbidity. Conventional treatment has been mainly by the use of antibiotics, limb elevation and analgesics. There is no consensus on the role of compression therapy in the management of cellulitis. This study was a comparative study of patients who presented with cellulitis at Kenyatta National Hospital. The study was set to determine the effect of compression therapy as an adjunct in the treatment of limb lower limb cellulitis The study period was between May 2014 and May 2015 Patients were randomly assigned into two groups through a computer generated program. Group A patients were managed with antibiotics, limbelevation, analgesia and elasticcompression therapy.. Group Bpatients were managed with elevation, antibiotics and analgesia. The antibiotic used was amoxyclavulinic acid while the analgesic was paracetamol and diclofenac. The parameters assessed wereoedema resolution, pain, tenderness and length of hospital stay. A total of eighty patients withcellulitis were recruited inbothgroupswith each arm having 40 patients. Group A patients who were managed with compression therapy had greater reduction in pain, tenderness and oedema as compared togroup B patients. The length of hospital stay was 10.2 days in group Aand 13.4 days in groupB. Elasticcompression therapy as demonstrated in this study is beneficial inthe management of cellulitis. It results in faster resolution of cellulitis with reduction in the length of hospital stay and with no increase in complications.
\end{abstract}

Keywords: Cellulitis, Compression Therapy, Outcome

\section{Introduction}

Cellulitis refers to the infectionof the subcutaneous tissues and the dermis. When not appropriately managed it can result in morbiditiesincluding necrotizing fasciitis and septicemia [1] The main stay of management hasbeenby the use of antibiotics, limb elevation and analgesics [1]. Compression therapy either dynamic or statichas not been routinely used in the management of cellulitis. [1,2] However its role in the treatment of lymphoedema and venous ulcer is well established. [3] Compression therapy is aimed at improving tissue perfusion at the cellular level by reducing the interstitial fluids and thus enabling better oxygen and nutrients delivery to the cells hence rapid healing of the wounds $[3,4]$. Compression therapy has demonstratedfaster healing of venous ulcersand reduction of oedema. [3, 4]. Its role in the treatment of cellulitis is still debatable. $[1,2]$ In this study we aimed to establish if compression therapy could be beneficial in the management of patients with cellulitis.

\section{Methods}

\section{Objective}

To determine theeffect of compression therapy as an adjunctin the treatment of limb cellulitis.

This was acomparative study of patients who presented with cellulitis at the Kenyatta National Hospital within the study duration of one year between May2014 and May 2015. The study was approved by the local ethics and research committee. Consent was sort from the patients to participate in the study. Patients with cellulitis with no ulceration or features ofsepticemiawere recruited. They were randomly assigned into two groups through a computer generated software. Variables determined werepain, tenderness, oedema resolution, White blood cells count, length of hospital stay 
and complications.

At the point of entry in the study patients had their blood taken for white blood cell count. This was repeated after two days. Patients had painassessment done using the pain visual analoguescale and tenderness using the tenderness evaluation study for the firstfour days following admission. Pain was graded into mild, moderate or severe using this scale. Tenderness was grade as; grade 1;feelspain on palpation, grade2; feels pain and winces on palpation, grade3; feels pain winces and withdraws limb on palpation, grade 4; doesn't allow palpation due to fear of severe pain. The limb had its measurement taken at a constant point from the nearby bonyprominence. This measurements were repeated after three days and on the sixth day. The oedemaextent was taken as the difference in girthbetween the affected limb and the normal limb. All patients were started on intravenous amoxyclavulanic acid at a recommended dose for weight. The analgesics given for the patients was a combination of paracetamol and diclofenac acid orally.

Group A patients had compressionwithelastic pressure garment that was done with an overlap of about 50 percent over soft pad dressings (figure 1,2). Prior to the placements of the stockings the limb girth measurements were taken. The compression garments were left onuntil the thirdday after which the limb girth measurement were taken again and on the $6^{\text {th }}$ day.

\section{Results}

A total of 80 patientswith cellulitis who made the inclusion criteriawere recruitedwith 40 patients in each group. The male to female ratio for group A patientswas 2:1while in group $\mathrm{B}$ was $3: 2$. The mean age for the patientsin group $\mathrm{A}$ was 39.8 and 37.5 years in group B. There was no significance differences in the causation of cellulitis in both groups with majority of the patients reporting trauma as the initiator of cellulitis.(Group A, 62.5 and group B 67.5 percent). Diabetismellitusaccounted for 20 percent ofpatients ingroupA and 25 percent in group B.

Majority of the patients in both groups presented with moderate to severe pains at the time of admission (figure 3 ). Therewas more reduction in pain severity in patients in group A both onthe $2^{\text {nd }}$ and $4^{\text {th }}$ day of assessment as compared to the patients in group B. (table 1). 45percent of the patients in group Ahad oedema reduction of more than 50 percent on day 3 and 95 percent on day 6as compared to 27.5 percent and 85 percent respectively among group B patients. (Table 2)
Majority of patients in both groups presented with grade 2 tenderness. (figure 4) There was significant reduction in tenderness in patients in groupA as compared to group Bon day 2 and 4. (table 3)

All patients had elevated white blood cells count at the time of admission. There was no statistical difference in both groups for the number of patients whose white blood cell counts returned to normal levels both onday 2 and 4 . The length of hospital stay in group A patients was 10. 6 days while in group B patients 13. 2 days. This was satistically significant.5 patients in group A had superficial ulcerations compared to 4 patients in group B. (This was not statistically significant) 3 patients in group A and 4Group B formed abscesses that were drained. this was not statistically significant).

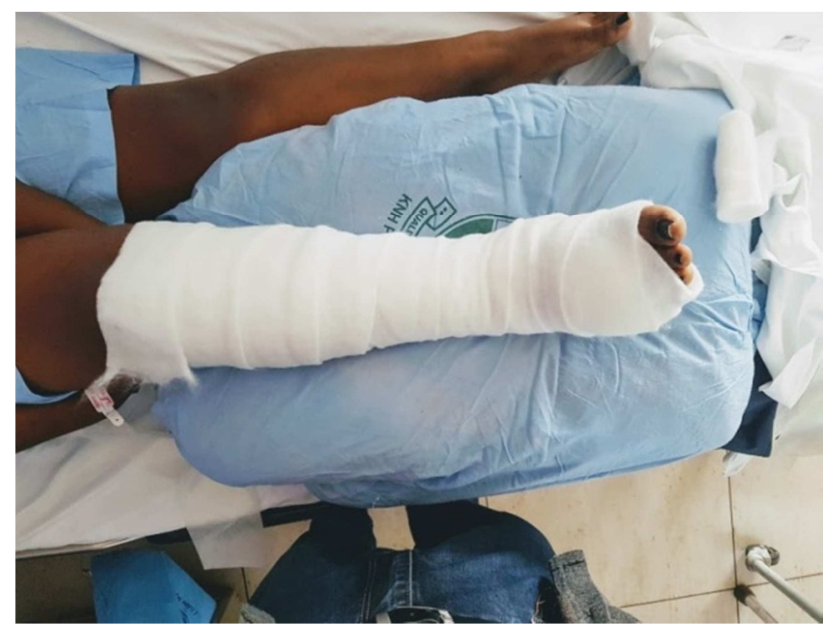

Figure 1. Soft pad applied on the limb with cellulitis.

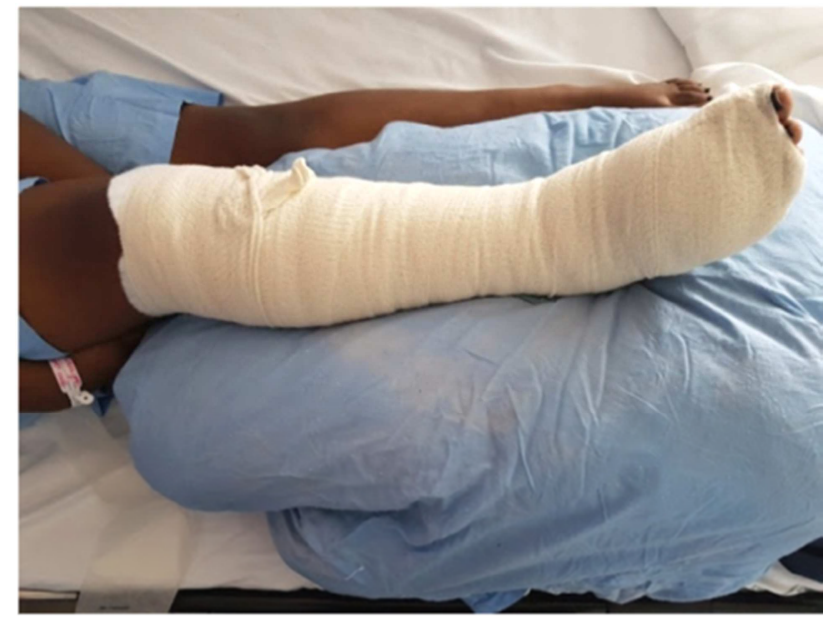

Figure 2. Elastic compression dressing applied over the limb with cellulitis.

Table 1. Evaluation of pain on day 2 and day 4. Group A patients hadgreater reductions in pain compared to group B patients.

\begin{tabular}{lllc}
\hline & Group A & Group B & Chisquare \\
\hline Pain assessment on day 2 & & & \\
$>50 \%$ change & $33(82.5)$ & $23(57.5)$ & 6 \\
$<50 \%$ change & $7(17.5)$ & $17(42.5)$ & 0.015 \\
Pain assessment on day 4 & & & \\
$>50 \%$ change & $37(92.5)$ & $26(65.0)$ & 0.003 \\
$<50 \%$ change & $3(7.5)$ & $14(35.0)$ & \\
\hline
\end{tabular}


Table 2. Evaluation of edema on day 2 and day 6, group A patients had more reduction in oedema compared to group B patients.

\begin{tabular}{lllll}
\hline & Group A & Group B & Chi square & P value \\
\hline Edema assessment on day 3 & & & & 0.016 \\
$<50 \%$ change & $22(55)$ & $29(72.5)$ & 2 & \\
$>50 \%$ change & $18(45)$ & $11(27.5)$ & & 0.0136 \\
Edema assessment on day6 & $2(5.0)$ & $6(15.0)$ & 2.2 & \\
$<50 \%$ change & $38(95.0)$ & $34(85.0)$ & & \\
$>50 \%$ change & & & \\
\hline
\end{tabular}

Table 3. Evaluation of tenderness score in patientson days 2 and4.

\begin{tabular}{|c|c|c|c|c|}
\hline & \multicolumn{2}{|c|}{ Cellulitis management } & \multirow{2}{*}{ Chi square } & \multirow{2}{*}{ P value } \\
\hline & Group A & Group B & & \\
\hline \multicolumn{5}{|c|}{ Tenderness assessment on day 2} \\
\hline$>50 \%$ change & $38(95.0)$ & $30(75.0)$ & 6.3 & 0.012 \\
\hline$<50 \%$ change & $2(5.0)$ & $10(25.0)$ & & \\
\hline \multicolumn{5}{|c|}{ Tenderness assessment on day 4} \\
\hline$>50 \%$ change & $39(97.5)$ & $33(82.5)$ & 5.0 & 0.025 \\
\hline$<50 \%$ change & $1(2.5)$ & $7(17.5)$ & & \\
\hline
\end{tabular}

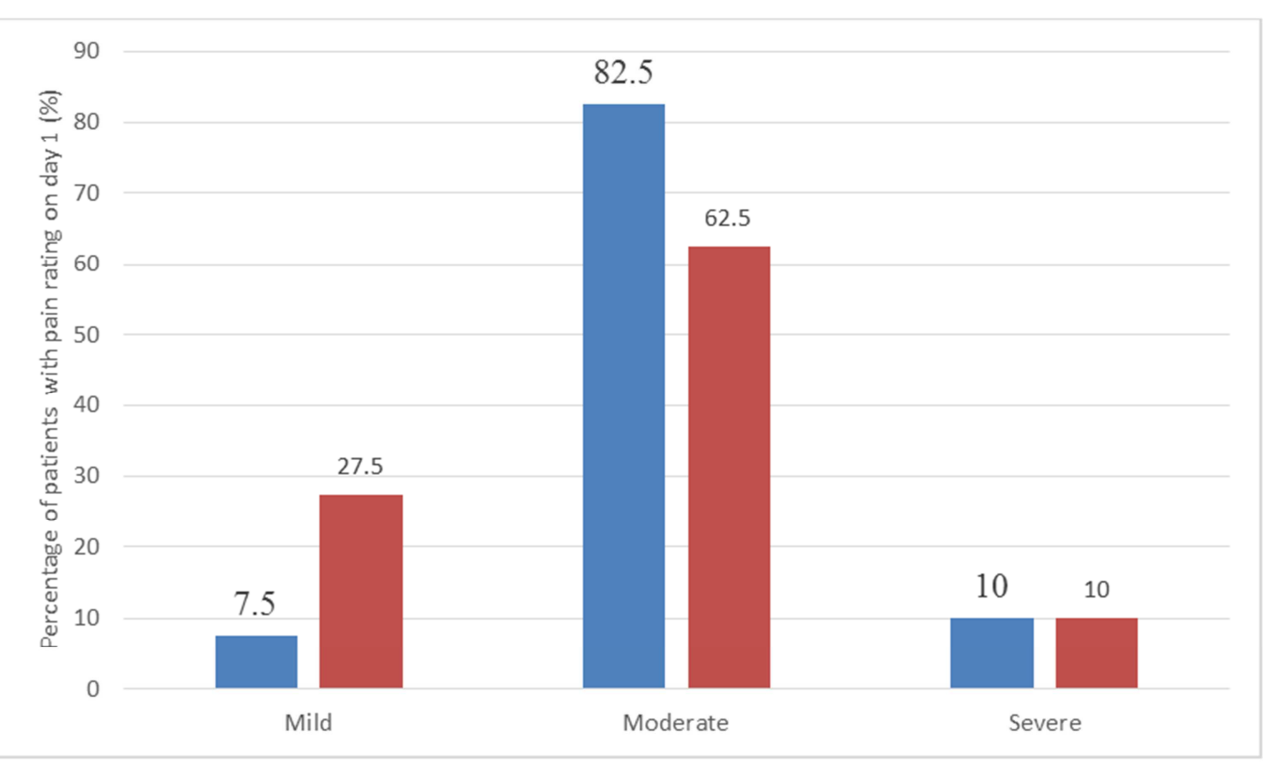

Figure 3. Baseline pain presentation on day 1, group A left, Group B, right.

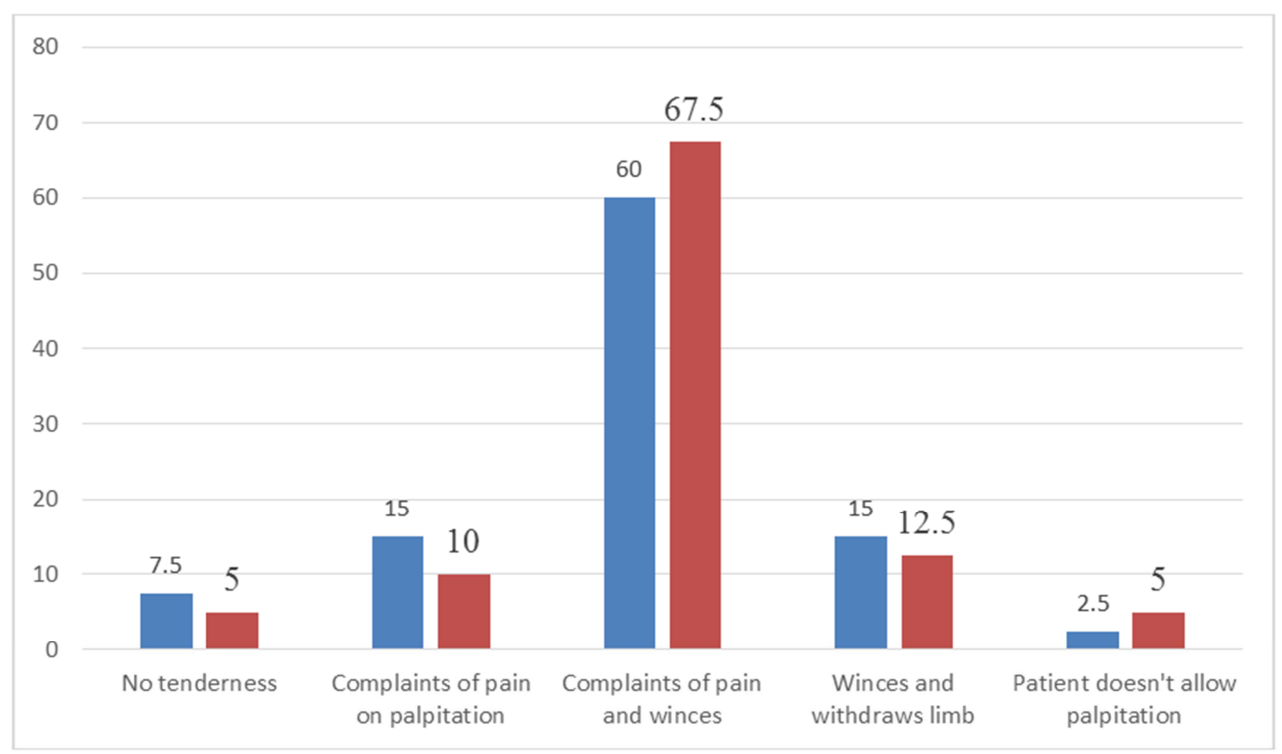

Figure 4. Tenderness in patients in group A(left) and group B(right) at the time of admission. 


\section{Discussion}

Cellulitisis a bacterial infection of the subcutaneous tissue. The commonest organisms are staph aureas and stretopcoccuspyogenes [1, 2]. The infectionsare associated with anintensiveinflammationresulting inmarkedswelling, pain and tenderness. The oedema reduces tissue perfusion resultingin decreased delivery of oxygen, nutrients andantibiotics. Despite the fact that oedema seems to prolong cellulitisand thus result in bad outcome, most of the treatment interventions have only focused on provision of antibiotics and pain management with minimal focus on the management of oedema other than limb elevation. [1, 2]. Compression therapy has actually been discouraged;sighting the theoretical risk of bacterial translocation to the blood stream. [1, 2] It hasalso been thought that applying compression stockings in the acute setting will bepainful to the patient and should therefore only be applied once the acute phase of the illness is over [1]. The findings of this studycontradicts the above held notions.

Patients who were managed on compression had a better and faster relief from pain. They also experienced less tenderness. These findings have also been noted in otherconditions where compression therapy has been utilized [4-8]. Patients on compression therapy withconditions such as venous ucers havereportedlesspain compared to those who were not. [5-7] The scientific basis of thisseems to be related to the fact that compression therapyincreases shear stress in the microcirculationresulting in the release of the ant inflammatorycytokines and antithrombotic from theendothelialcells [9]. Among the anti inflammatory cytokines elevated in patients with compression therapyis theIL-1Ra. [10] Pro inflammatory cytokines. Metalloproteinases has also been shown to be decreased in patients with compression therapy [10]. Compression therapy therefore seems to influence the inflammatory responsebydown regulation the proinflammatory cytokines and upregulating the antinflammatory cytokines and thusless pain. tenderness and oedema.

The reduction in the length of hospital stay is probably related to the rapid elimination ofoedemain the patients who were managed with compression dressings. Oedema has been shown to have deleterious effects not only on healing of the wounds but alsoinpredisposition to infection. [11, 12] It reduces tissue perfusion and thus reduces delivery of nutrients, oxygen and antibiotics. Lymphoedema fluidhas high protein concentration which encourages bacterialproliferation and growth. [11, 12] Oedema has also been noted to inactivatenormal skin antimicrobialproperties resulting in increased propensity forskin infections. [11] While elevation of the limb tend to assist in the reduction of oedema this is largely a passive process resulting in fluid shifts based on the pressure difference. For it to work the entire limb must be elevated above the level of the heart which may be impractical in some patients. Compressiontherapy on the other hand increases the interstitial pressures and thus reduces the exudates fromthe capillaries while encouraging venousreturn.

All the patients had an elevated white blood cell counts at the time of admission. Therewas however no statistical difference in the return to normal levels between the two groups. Leucocytes countis however unlikely to be a sensitive nor specific marker of cellulitis progression. C reactive protein or procalcitonin would have been better markers and should probably be used in future studies.

\section{Conclusion}

This study demonstrates thatelastic compression therapy is of benefit in the management of uncomplicated cellulitis. It results in reduction in pain, tenderness as well as oedema with an overall effect of reduction in the length of hospital stay. There is no increase in complications. Elastic compression therapy should thus be encouraged in the routine management of uncomplicated cellulitis.

\section{Conflict of Interest Statement}

All the authors do not have any possible conflicts of interest.

\section{References}

[1] Raff AB, Kroshinsky D. Cellulitis: A Review. JAMA 2016; 316(3):325-337.

[2] Crest June 2005. www.acutemed.co.uk/docs/Cellulitis guidelines, CREST, 05.pdf

[3] Moffat. C., O'Hare. L. Venous leg ulceration: treatment by high compression bandaging.' Ostomy Wound Management. 1995; 41: 16-25.

[4] Moffat C., O'Hare L., Charles H., Short-stretch bandaging in the treatment of venous legulcers.' J. Wound Care 1999; 8: 303-304.

[5] Lucia Helena Rocha Vilela, Geraldo MagelaPain Assessment in Patients with Venous Leg Ulcer Treated by Compression TherapyWithUnnas BootJ Tissue SciEng, June 2016 7:171. doi:10.4172/2157-7552.1000171

[6] Brijesh NairCompression therapy for venous leg Indian Dermatol Online J. 2014 Jul-Sep; 5(3): 378-382. Doi: $10.4103 / 2229-5178.137822$

[7] Treadwell T, Fowler E, Jensen BB. Management of Edema in Wound Care: A CollaborativePractice Manual for Health Professionals, Fourth Edition. Eds.-Carrie Sussman and BarbaraBates Jensen, Lippincott, Wilkins, and Williams, New York, NY, 2012.

[8] Treadwell TA. Demystifying Compression: Answers That May Surprise You. Online continuing education webinar, http://www.slideshare.net/3MSkinWoundCare/3m-health-carecompression-webcast. 6/28/11.

[9] Beidler SK, Douillet CD, Berndt DFet al. Inflammatory cytokine levels in chronic venousInsufficiency ulcer tissue before and after compression therapy. J VascSurg2009; 49:1013-20. 
[10] Beidler SK, Douillet CD, Berndt DFetal. Multiplexed analysis of matrix metalloproteinase's in leg ulcer tissue of patients withchronic venousinssufficiency before and after compression therapyWound Repair Regen2008; 16:642-8.

[11] Treadwell TA, Macdonald J. Infection, Edema, and
Compression Therapy: Are TheyCompatible? Poster presentation Symposium on Advanced Wound Care, San Diego, California, April 6-9, 2017.

[12] Woo PC, Lum PN, Wong SS, et al. 'Cellulitis complicating lymphoedema. Eur J ClimicrobiolInfect Dis 2000; 19:294. 